\title{
Compensatory quadrant-hyperhidrosis after contralateral intrathoracic surgery: a case report
}

\author{
Stefan Brodoehl, Otto Wilhelm Witte and Albrecht Guenther
}

\begin{abstract}
Introduction: Unilateral hyperhidrosis can be a neurological manifestation of irritations of the central or peripheral nervous system.

Case presentation: We present the case of a 67-year-old German man who had hyperhidrosis of his right upper body quadrant (including face, arm, and chest) following intrathoracic surgery of a left-sided pleural lipoma.

Conclusion: An isolated unilateral hyperhidrosis might occur after intrathoracic surgery. Besides anticholinergic drugs the use of botulinum toxin should be considered.
\end{abstract}

Keywords: Botulinum toxin, Intrathoracic surgery, Unilateral hyperhidrosis

\section{Introduction}

Anhidrosis and hyperhidrosis can be neurological manifestations of irritations of the central or peripheral nervous system $[1,2]$. There are described causes such as injuries, tumors, infarcts or hemorrhages of the brain or the medulla.

\section{Case presentation}

A 67-year-old German man admitted to our botulinum toxin clinic complained about extensive sweating of his right upper body including his right facial area, right arm, and chest, whereas the left side of his body appeared to be 'summer-dry'. At the time of his presentation at our clinic the patient reported a subjective reduction of quality of life. The massive hyperhidrosis made him feel uncomfortable in the company of strangers and therefore kept him from taking part in social activities.

Symptoms started some weeks after tumor extirpation of a left-sided pleural lipoma via an anterior-posterior thoracotomy at the 5th intercostal space in conjunction with a partial pleurectomy. After being released from hospital, he experienced contralateral hyperhidrosis which started in the face spreading downwards.

Clinical neurological examination together with ophthalmological tests yielded a normal status appropriate to the patient's age. Sympathetic skin nerve action potentials [3] were recorded in both arms and legs and revealed a significantly decreased sympathetic activity in the left arm. Pharmacological pupil function test (cocaine and phenylephrine eye drops) showed no discrepancy on the left side. In particular, Horner's syndrome or hypesthesia were not found. In addition, scintigraphy showed no proof of a reduced function of salivary glands. After physical activity, a starch-iodine preparation was performed, revealing significant hyperhidrosis of the right upper body together with a relevant temperature difference measured on the chest (right $30.5^{\circ} \mathrm{C}$, left $33.7^{\circ} \mathrm{C}$ ). Lung auscultation, before and after physical exertion, yielded right-sided bronchial spasm post-exercise.

Treatment was started with bornaprine: a central anticholinergic drug. A starting dose of two mg per day increasing to six mg did not lead to a relevant clinical improvement but produced intolerable side effects.

Due to a considerable subjective impairment, we decided on a test injection of botulinum toxin type A. A total of 20 units at three injection points on the right side of the patient's forehead and a total of 40 units at six injection points on his right upper body were administered. Some improvement was achieved and therapy was repeated in a three-month interval.

* Correspondence: stefan.brodoehl@med.uni-jena.de

Hans Berger Department of Neurology, Jena University Hospital, Erlanger Allee 101, D 07747, Jena, Germany 
Table 1 Cases of localized unilateral hyperhidrosis in the literature excluding isolated facial hyperhidrosis

Cause of hyperhidrosis

Idiopathic unilateral hyperhidrosis
Intrathoracic neoplasia

Stroke - brainstem infarction

Stroke - cerebral infarction

\section{Postinterventional complications}

\section{Reference}

Cunliffe et al. [7]

van de Kerkhof et al. [8]

Dworin and Sober [9]

Fernández and Armijo [10]

Querol Nasarre et al. [11]

Köse and Baloglu [12]

Boyvat et al. [13]

Kreyden et al. [14]

Kocyigit et al. [15]

\section{Cases}

3

1

1

1

1

1

1

1

1

Middleton [16]

Walsh et al. [17]

McCoy [18]

Wang et al. [19]

McEvoy et al. [20]

Lindsay et al. [4]

Umeki et al. [21]

Lambert et al. [22]

Yamauchi et al. [23]

Slabbynck et al. [24]

Lee and Greenstone [25]

Nishimura et al. [26]

Sribnick and Boulis [27]

Mon and Mizotani [28]

Korpelainen et al. [29]

Rey et al. [30]

Rousseaux et al. [31]

Sato and Nitta [32]

Pellecchia et al. [33]

Labar et al. [34]

Sakashita et al. [35]

Kim et al. [36]

Bassetti and Staikov [37]

Smith [38]

Faruqi et al. [39]

Belin and Polo [40]

Aşik et al. [41]
Therapy

local anticholinergic*

no

local $\mathrm{Al}_{2} \mathrm{Cl}_{6}$ *

local $\mathrm{Al}_{2} \mathrm{Cl}_{6}$ *

no

no

antidepressant

botulinum toxin $A$ *

no

no

no

no

no

no

no

no

local radiotherapy *

no

no

no

local radiotherapy *

sympathectomy *

no

no

no

no

no

no

no

no

no

no

no

no

botulinum toxin $A$ * local radiotherapy * 
Spinal cord pathology

$\begin{array}{ll} & \text { Pool [42] } \\ & \text { Baskan et al. [43] } \\ & \text { Kilinçer et al. [44] } \\ & \text { Gorman [45] }\end{array}$

Sweat glands pathology

Kopera and Soyer [46]
Ruiz de Erenchun et al. [47]
Parslew and Lewis-Jones [48]

Others (Buerger's disease) hemilaminectomy *

botulinum toxin $\mathrm{A}^{*}$

no

improved bedding *

appetite depressant * antidepressant *

no

no

(*) indicates successful therapy, $\left(\mathrm{Al}_{2} \mathrm{Cl}_{6}\right)$ aluminum hexachloride.

\section{Discussion}

The localized unilateral hyperhidrosis in the present case developed after intrathoracic surgery. Therefore, we hypothesize that the quadrant-hyperhidrosis of the right upper body is a (hyper-) compensation of a disturbed sympathetic innervation of the contralateral left side due to a surgical lesion of the cervical sympathetic chain. The lesion is assumed to be situated in the endothoracic fascia, where the cervical sympathetic fibers are closely related to the apical pleura [4]. Presumably caused by a disturbed negative feedback of afferent sympathetic signals, the sweating center in the hypothalamus generates an increased positive feedback signal that induces severe sweating on the body side contralateral to the sympathetic lesion [5].

Table 1 provides an overview of known cases of localized unilateral hyperhidrosis in the literature and (if included) briefly describes applied therapies and their effectiveness. Taken together most successful therapy strategies included the application of botulinum toxin type A. Besides sympathectomy treatment with antidepressants or local therapy with aluminum hexachloride have proven effective. Although not effective in the present case, the use of oral anticholinergic drugs is a good therapeutic alternative especially because Wolosker et al. [6] have recently shown the potential of oxybutynin in treating localized hyperhidrosis.

Another relevant clinical aspect might be a bronchial spasm of the right lung in the course of physical exertion due to an overwhelming activity of the left-sided parasympathetic nervous system. In our case, the patient had no medical history of chronic lung disease; although an obstructive lung disease cannot be excluded beyond doubt. This additional feature might be an interesting physiological aspect that has - to the best of our knowledge - never been reported before.

\section{Conclusion}

An isolated unilateral hyperhidrosis is a rare complication after intrathoracic surgery that potentially reduces the quality of life. As therapeutic options anticholinergic drugs or the use of botulinum toxin could be considered.

\section{Consent}

Written informed consent was obtained from the patient for publication of this manuscript and accompanying images. A copy of the written consent is available for review by the Editor-in-Chief of this journal.

\section{Competing interests}

The authors declare that they have no competing interests.

\section{Authors' contribution}

SB and AG performed the clinical examination, analyzed and interpreted the diagnostic findings, and applied the pharmacological therapy. Conception and discussion was performed by all authors. The main writing was done by SB. All authors read and approved the final manuscript.

\section{Acknowledgments}

We thank our patient who gave written permission to publish his case. No external funding was obtained.

Received: 24 August 2012 Accepted: 4 December 2012

Published: 18 January 2013

\section{References}

1. Leung AK, Chan PY, Choi MC: Hyperhidrosis. Int J Dermatol 1999, 38:561-567.

2. Wasner G, Maag R, Ludwig J, Binder A, Schattschneider J, Stingele R, Baron R: Harlequin syndrome-one face of many etiologies. Nat Clin Pract Neurol 2005, 1:54-59.

3. Lidberg L, Wallin BG: Sympathetic skin nerve discharges in relation to amplitude of skin resistance responses. Psychophysiology 1981, 18:268-270.

4. Lindsay DC, Freeman JG, Record CO: Unilateral hyperhidrosis associated with underlying intrathoracic neoplasia. Thorax 1986, 41:814-815.

5. Chou SH, Kao EL, Lin CC, Chang YT, Huang MF: The importance of classification in sympathetic surgery and a proposed mechanism for compensatory hyperhidrosis: experience with 464 cases. Surg Endosc 2006, 20:1749-1753. 
6. Wolosker N, Campos JR, Kauffman P, Munia MA, Neves S, Jatene FB, PuechLeao P: The use of oxybutynin for treating facial hyperhidrosis. An Bras Dermatol 2011, 86:451-456.

7. Cunliffe WJ, Johnson CE, Williamson DM: Localized unilateral hyperhidrosis-a clinical and laboratory study. Br J Dermato/ 1972, 86:374-378.

8. van de Kerkhof PC, den Arend JA, Bousema MT, Stolz E: Localized unilatera hyperhidrosis. Br J Dermatol 1987, 117:779-782.

9. Dworin A, Sober AJ: Unilateral segmental hyperhidrosis. Response to $20 \%$ aluminum chloride solution and plastic wrap. Arch Dermatol 1978, 114:770-771.

10. Fernández G, Armijo M: Unilateral facial circumscribed hyperhidrosis. Acta Derm Venereol 1985, 65:445-447.

11. Querol Nasarre I, Jarauta Salvador F, Alberdi Ibáñez I, Cisneros Lanuza T, Expósito Rando A: Paroxysmal unilateral hyperhidrosis. Neurologia 1994, 9:419-422.

12. Köse $\mathrm{O}$, Baloglu $\mathrm{H}$ : Idiopathic unilateral circumscribed hyperhidrosis. Int $\mathrm{J}$ Dermatol 1997, 36:209-210.

13. Boyvat A, Pişkin G, Erdi H: Idiopathic unilateral localized hyperhidrosis. Acta Derm Venereol 1999, 79:404-405.

14. Kreyden OP, Schmid-Grendelmeier P, Burg G: Idiopathic localized unilateral hyperhidrosis: case report of successful treatment with botulinum toxin type A and review of the literature. Arch Dermatol 2001, 137:1622-1625.

15. Kocyigit P, Akay BN, Saral S, Akbostanci C, Bostanci S: Unilateral hyperhidrosis with accompanying contralateral anhidrosis. Clin Exp Dermatol 2009, 34:e544-e546.

16. Middleton WG: Bronchial carcinoma with pleural spread causing unilateral thoracic hyperhidrosis. Br Med J 1976, 2:563.

17. Walsh JC, Low PA, Allsop JL: Localized sympathetic overactivity: an uncommon complication of lung cancer. J Neurol Neurosurg Psychiatry 1976, 39:93-95.

18. McCoy BP: Apical pulmonary adenocarcinoma with contralateral hyperhidrosis. Arch Dermatol 1981, 117:659-661.

19. Wang $Y T$, Singh D, Poh SC: Hemihyperhidrosis and intrathoracic malignancy. Singapore Med J 1981, 22:86-88.

20. McEvoy M, Ryan E, Neale G, Prichard J: Unilateral hyperhydrosis-an unusual presentation of bronchial carcinoma. Ir J Med Sci 1982, 151:51-52.

21. Umeki S, Tamai H, Yagi S, Soejima R, Higashi Y: Harlequin syndrome (unilateral flushing and sweating attack) due to a spinal invasion of the left apical lung cancer. Rinsho Shinkeigaku 1990, 30:94-99.

22. Lambert M, Kanyinda JM, Richard F, Sindic C: Unilateral hyperhidrosis associated with intrathoracic lgD lambda myelomatous tumour. Clin Oncol (R Coll Radiol) 1993, 5:65-66.

23. Yamauchi $Y$, Kobayashi T, Nagaro T, Yamamoto H, Kimura S, Arai T: A case of hemifacial hyperhidrosis on the opposite side of the pancoast tumor Masui 1994, 43:924-926.

24. Slabbynck H, Bedert L, De Deyn PP, Galdermans D, Coolen D: Unilateral segmental hyperhidrosis associated with pulmonary adenocarcinoma. Chest 1998, 114:1215-1217.

25. Lee WY, Greenstone M: Unilateral hyperhidrosis in malignant mesothelioma. Am J Med Sci 2011, 342:332.

26. Nishimura J, Tamada Y, Iwase S, Kubo A, Watanabe D, Matsumoto Y: A case of lung cancer with unilateral anhidrosis and contralateral hyperhidrosis as the first clinical manifestation. J Am Acad Dermatol 2011, 65:438-440.

27. Sribnick EA, Boulis NM: Treatment of Harlequin syndrome by costotransversectomy and sympathectomy: case report. Neurosurgery 2011, 69:E257-E259.

28. Mon Y, Mizotani M: A case of hemi-hyperhidrosis and non-paralytic pontine exotropia due to brainstem infarction. Rinsho Shinkeigaku 1992, 32:718-721.

29. Korpelainen JT, Sotaniemi KA, Myllylä W: Ipsilateral hypohidrosis in brain stem infarction. Stroke 1993, 24:100-104.

30. Rey A, Martí-Vilalta JL, Abellán MT: Contralateral hyperhidrosis secondary to the pontine infarct. Rev Neurol 1996, 24:459-460.

31. Rousseaux M, Hurtevent JF, Benaim C, Cassim F: Late contralateral hyperhidrosis in lateral medullary infarcts. Stroke 1996, 27:991-995.

32. Sato K, Nitta E: Pontine hemorrhage presenting with Foville syndrome and transient contralateral hyperhidrosis. Rinsho Shinkeigaku 2000, 40:271-273.

33. Pellecchia MT, Criscuolo C, De Joanna G, D'Amico A, Santoro L, Barone P: Pure unilateral hyperhidrosis after pontine infarct. Neurology 2003, 61:1305.
34. Labar DR, Mohr JP, Nichols FT, Tatemichi TK: Unilateral hyperhidrosis after cerebral infarction. Neurology 1988, 38:1679-1682.

35. Sakashita Y, Kakuta K, Kakuma K, Matsuda H: Unilateral persistent hyperhidrosis after ischemic stroke. Rinsho Shinkeigaku 1992, 32:454-456.

36. Kim BS, Kim Yl, Lee KS: Contralateral hyperhidrosis after cerebral infarction. Clinicoanatomic correlations in five cases. Stroke 1995, 26:896-899.

37. Bassetti C, Staikov IN: Hemiplegia vegetativa alterna (ipsilateral Horner's syndrome and contralateral hemihyperhidrosis) following proximal posterior cerebral artery occlusion. Stroke 1995, 26:702-704.

38. Smith CD: A hypothalamic stroke producing recurrent hemihyperhidrosis. Neurology 2001, 56:1394-1396.

39. Faruqi $S$, Redmond G, Ram P, Owens VB, Sangster G, Barrett JA: Hemihyperhidrosis in cerebral infarction. Age Ageing 2004, 33:514-515.

40. Belin $\mathrm{EE}$, Polo J: Treatment of compensatory hyperhidrosis with botulinum toxin type A. Cutis 2003, 71:68-70.

41. Așik ZS, Orbey BC, Așik I: Sympathetic radiofrequency neurolysis for unilateral lumbar hyperhidrosis: a case report. Agri 2008, 20:37-39.

42. Pool JL: Unilateral thoracic hyperhidrosis caused by osteoma of the tenth dorsal vertebra; case report. J Neurosurg 1956, 13:111-115.

43. Baskan EB, Karli N, Baykara M, Cikman S, Tunali S: Localized unilateral hyperhidrosis and neurofibromatosis type 1: case report of a new association. Dermatology 2005, 211:286-289.

44. Kilinçer C, Oztürk L, Hamamcioglu MK, Altunrende E, Cobanoglu S: An upper thoracic spinal cord tumor presenting as hemifacial hyperhidrosis. Surg Neurol 2007, 68:461-463. discussion 463.

45. Gorman PH: Unilateral hyperhidrosis from a contralateral source in an individual with C4 complete tetraplegia. J Spinal Cord Med 2010, 33:428-430

46. Kopera D, Soyer HP: Eccrine hamartoma of the sweat glands simulating localized unilateral hyperhidrosis. Hautarzt 1992, 43:587-589.

47. Ruiz de Erenchun F, Vázquez-Doval FJ, Contreras Mejuto F, Quintanilla E: Localized unilateral hyperhidrosis: eccrine nevus. J Am Acad Dermatol 1992, 27:115-116.

48. Parslew R, Lewis-Jones MS: Localized unilateral hyperhidrosis secondary to an eccrine naevus. Clin Exp Dermatol 1997, 22:246-247.

49. Baker H: Unilateral hyperhidrosis. Br J Dermatol 1988, 118:588-589.

doi:10.1186/1752-1947-7-24

Cite this article as: Brodoehl et al:: Compensatory quadranthyperhidrosis after contralateral intrathoracic surgery: a case report. Journal of Medical Case Reports 2013 7:24.

\section{Submit your next manuscript to BioMed Central and take full advantage of:}

- Convenient online submission

- Thorough peer review

- No space constraints or color figure charges

- Immediate publication on acceptance

- Inclusion in PubMed, CAS, Scopus and Google Scholar

- Research which is freely available for redistribution 